The interplay between country stereotypes and perceived brand globalness/localness as

$$
\text { drivers of brand preference }
$$

Georgios Halkias (corresponding author)

Assistant Professor

University of Vienna, Faculty of Business, Economics and Statistics

Department of International Marketing

Vasileios Davvetas

Ph.D. Candidate

University of Vienna, Faculty of Business, Economics and Statistics

Department of International Marketing

Adamantios Diamantopoulos

Professor

University of Vienna, Faculty of Business, Economics and Statistics

Department of International Marketing

"This is the accepted version of a paper published in the Journal of Business Research: Halkias, G., Davvetas, V., \& Diamantopoulos, A. (2016). The interplay between country stereotypes and perceived brand globalness/localness as drivers of brand preference. Journal of Business Research, 69, 3621-3628. https://doi.org/10.1016/j.jbusres.2016.03.022"

(C) 2016. This manuscript version is made available under the CC-BY-NC-ND 4.0 license http://creativecommons.org/licenses/by-nc-nd/4.0/

Acknowledgement: The authors acknowledge the Austrian Science Fund (FWF) for supporting this study (Research Grant: P26740-G11). 


\title{
The interplay between country stereotypes and perceived brand globalness/localness as drivers of brand preference
}

\begin{abstract}
This study integrates country-of-origin and global/local branding literatures to investigates how country- and brand-specific factors influence consumer preferences. Drawing from the Stereotype Content Model (SCM) in social psychology, we operationalize country perceptions by means of warmth and competence judgments and juxtapose them with consumers' perceptions of brand globalness and localness to predict brand attitudes and subsequent purchase intentions. An empirical study involving a series of well-known brands from different countries and product categories shows that $(a)$ the SCM can effectively capture country-of-origin effects, $(b)$ judgments of competence impact consumer preferences above and beyond the positive effects of brand globalness and localness, and (c) country stereotypes (particularly the dimension of warmth) interact with perceptions of brand globalness in determining brand attitude, whereas perceived brand localness has an independent effect. Theoretical and managerial implications of the findings are discussed and directions for future research identified.
\end{abstract}

Keywords: Country Stereotypes, Stereotype Content Model, Global Brands, Local Brands 


\section{The interplay between country stereotypes and perceived brand globalness/localness as drivers of brand preference}

\section{Introduction}

Consumers in today's globalized marketplace make purchase decisions over a multitude of brands which typically vary both with regard to their market presence and availability and with regard to their national origin. Accordingly, international marketing managers have been trying to capitalize on their brands' global reach and localness associations as well as on favorable country-of-origin (COO) perceptions in order to leverage brand equity. At the same time, international marketing researchers have been focusing on clarifying how consumer preferences are differentially influenced by a brand's global/local nature (Steenkamp, Batra, \& Alden, 2003) and/or its COO associations (Herz \& Diamantopoulos, 2013). This increased academic and managerial interest has generated two main streams of inquiry in international marketing, namely global/local branding and COO research.

Global/local branding research revolves around the implications of a brand's global or local nature. Global brands are brands having "global awareness, availability, acceptance and desirability and are often found under the same name with consistent positioning, image, personality, look and feel in major markets enabled by standardized and centrally coordinated marketing strategies and programs" (Özsomer \& Altaras, 2008, p.1). Local brands, on the other hand, are defined as brands "only available in a specific geographical region" or a "concentrated market” (Dimofte, Johansson, \& Ronkainen, 2008, p.120). This stream of research suggests that brand globalness associations strengthen brand preference by boosting consumers' perceptions of quality, prestige, and credibility (Steenkamp et al., 2003; Özsomer, 2012), while brand localness 
associations create brand value by building on the local identity, supporting the local culture, and adapting the brand to local tastes and needs (Özsomer, 2012; Schuiling \& Kapferer, 2004).

COO research, on the other hand, focuses on the potential benefits a brand can draw through its association with a particular country of origin, regardless of whether this country is the actual country of manufacture (Jaffe \& Nebenzahl, 2006). Several studies have demonstrated that products and brands which are essentially identical in every aspect may be rated differently depending on their origin; a phenomenon referred to as the COO effect (Wilcox, 2015). In general, COO research indicates that brand responses tend to be influenced according to the valence of the perceptions consumer attach to the corresponding country of origin (Maheswaran \& Chen, 2009).

Recent debate in international marketing literature has raised concerns as to whether both of these research streams are indeed useful in explaining and predicting brand preference. On the one hand, $\mathrm{COO}$ critics argue that $\mathrm{COO}$ has lost its importance in a globalized marketplace. For instance, Usunier (2006, p.61) argues that the "COO effect is no longer a major issue in international marketing operations: multinational production, global branding, and the decline of origin labelling in WTO rules tend to blur the COO issue and to lessen its relevance." Moreover, COO research has been criticized for lacking a solid theoretical background (Usunier \& Cestre, 2008) and for being "generally void of meaningful managerial guidelines" (Samiee, 2011, p.473). On the other hand, some authors have challenged the notion of universal and unconditional global brand preference (Riefler, 2012), while others have suggested that COO is a salient factor in consumer evaluations even in an era of global brand prevalence (Wilcox, 2015). Indeed, there is evidence showing that $\mathrm{COO}$ might play an even stronger role than brand globalness in determining brand evaluations (Sichtmann \& Diamantopoulos, 2013). Overall, this debate brings about an unresolved research issue of considerable theoretical and managerial relevance. Theoretically, it challenges two well-established areas in international marketing research and 
calls for an integrative approach that focuses on investigating their relative contribution in explaining consumer behavior. From a practitioner standpoint, this debate complicates managerial decision making as it puts into question investments in brand building strategies anchored either on globalness/localness or COO associations.

The present paper aims at throwing light on the above debate by simultaneously investigating the effects of brand- and country-specific factors as drivers of brand preference. By juxtaposing global branding and COO literature, we try to $(a)$ establish whether brand globalness/localness and country stereotypes are both relevant in predicting brand preference, $(b)$ identify which of the two is more influential in the presence of the other, and (c) explore whether there is an interaction between the perceived globalness/localness of the brand and the stereotype associated with the brand origin. To this end, we develop a conceptual model incorporating variables capturing the global/local nature of a brand - namely perceived brand globalness (PBG; Steenkamp et al., 2003) and perceived brand localness (PBL; Swoboda, Pennemann \& Taube, 2012) - and juxtapose them with stereotypical beliefs about the brand's origin captured by the dimensions of competence and warmth of the Stereotype Content Model (SCM; Fiske, Cuddy, Glick, \& Xu, 2002). We empirically test the proposed model using several well-known brands from different countries and product categories.

From a theoretical perspective, we contribute to international marketing literature by bringing together two parallel research streams and examining the impact of COO stereotypes, perceived brand globalness/localness on brand attitudes and, ultimately, purchase intentions. As such, our study offers evidence regarding the relative strength of these constructs as drivers of brand attitude, thus highlighting the relevance of the respective theoretical domains. Moreover, by approaching the $\mathrm{COO}$ construct through the lenses of the SCM, our study contributes toward a more theoretically-driven investigation of $\mathrm{COO}$ effects, commonly criticized for lacking 
substantive theoretical backing (Samiee, 2011; Usunier \& Cestre, 2008). Importantly, to the best of our knowledge, our study represents the first empirical attempt to explore the potential interplay between stereotypical judgments of the brand origin and consumers' perceptions of the globalness/localness of a brand. As such, it offers important insights on the potential synergistic role of country- and brand-specific characteristics and, especially, how perceptions of warmth and competence of the brand origin may interact with perceived brand globalness and/or localness to determine brand preference.

In managerial terms, our findings offer important implications on the effectiveness of brand globalness, localness and country stereotypes as alternative bases of strategic brand positioning. This is particularly relevant for brands that have the capability to exploit more than one of the above options, but lack relevant evidence as to which alternative would yield better results. For example, Toyota is a brand which, in the US market, could potentially benefit from all three positioning options. Specifically, it could be effectively positioned by $(a)$ promoting its worldwide availability and demand (globalness), (b) highlighting its ties with the American communities through employing local employees for its US-based factories (localness), or (c) emphasizing its Japanese origin, which is associated with high efficiency and technological competence (competence-based country stereotype). Our research provides empirical insights into the potential effectiveness of these alternative options, thus, assisting positioning strategy decisions. It also provides insights about which strategies might be most appropriate for brands with different origins and suggests that positioning the brand as global might not be equally effective across countries with diverse stereotype contents in terms of warmth and competence. 


\section{Conceptual model and research hypotheses}

To build our conceptual model, we first develop hypotheses regarding the influence of brand-specific factors (i.e., perceived brand globalness and localness) and then discuss hypothesized effects of country-specific factors based on the two SCM dimensions (i.e., warmth and competence). As Figure 1 illustrates, we consider the simultaneous effects of all these factors on brand attitude and through it on brand purchase intentions.

\section{FIGURE 1 ABOUT HERE}

\subsection{Brand-specific factors: Perceived Brand Globalness and Perceived Brand Localness}

Perceived brand globalness is defined as the extent to which "consumers believe that a brand is marketed in multiple countries and is recognized as global in these countries" (Steenkamp et al., 2003, p.54). Brand globalness has become a prominent construct in branding research following the decision of many international companies to disengage from their multidomestic local brand focus and turn to the development of global brands (Schuiling \& Kapferer, 2004). Beyond the significant supply-side benefits of a streamlined global brand portfolio (e.g., extensive economies of scale, standardized operations, marketing and R\&D synergies), global brands have been found to enjoy strong consumer interest, thus rendering global availability an important source of competitive advantage (Steenkamp \& de Jong, 2010)

Global brands have been consistently associated by consumers with $(a)$ strong functional value, $(b)$ enhanced symbolic benefits, and $(c)$ identity-expressing capabilities. Consumers perceive global brands as brands of high quality (Özsomer, 2012; Steenkamp et al., 2003; 
Swoboda, Pennemann \& Taube, 2012). These perceptions are based on consumer inferences regarding global brands' ability to successfully satisfy worldwide demand (Holt, Quelch \& Taylor, 2004). Moreover, the standardized character of many global brands, their long-term brand investments, as well as their need to sustain a worldwide reputation operate as credibility signals which subsequently reduce consumers' perceived risk (Özsomer \& Altaras, 2008). At the same time, global brands are seen as sources of symbolic values such as status, prestige, social approval, excitement and modernity (Özsomer, 2012; Steenkamp et al., 2003). In this context, Dimofte et al. (2008) describes an affective component in consumers' preference for global brands which relates to the positive feelings global brands generate to consumers, while Swoboda et al. (2012) find evidence of emotional value associated with global retailers. Recent research has also revealed a novel, identity-based function of global brands, whereby consumers view global brands as vehicles to express a modern self-image, promote themselves as global citizens, and signal a cosmopolitan identity to their reference groups (Strizhakova \& Coutler, 2014; Xie, Batra, \& Peng, 2015). Along these lines, global brand possession provides access to the "global myth" (Holt et al., 2004) and opens a pathway of belongingness to the global consumer culture (Alden, Steenkamp, \& Batra, 2006).

Through all these influences, global brands enjoy positive consumer responses, ranging from positive brand attitudes to increased tolerance toward global brand price premiums (Davvetas, Sichtmann, \& Diamantopoulos, 2015). We, thus, expect that strengthening brand globalness perceptions will result in more favorable brand attitudes. In addition, as Chaudhuri and Holbrook (2001) argue, positive overall evaluations of a brand should then positively contribute to the behavioral intention for that particular brand. Therefore, we expect that the positive effect of perceived brand globalness on brand attitude will subsequently translate into a stronger purchase intention. 
$\mathrm{H}_{1 \mathrm{a}}$ : Perceived brand globalness has a positive effect on purchase intentions by generating more positive brand attitudes.

Despite the many beneficial associations of global brands, being "global" is not the only way to brand success (Steenkamp \& de Jong, 2010). Research has identified consumer forces that drive consumers away from global brands and bring them toward local alternatives (Van Ittersum \& Wong, 2010). Modern markets include consumers segments exhibiting localized preferences such as ethnocentric consumers, who are morally inclined to the purchase of local products as a means to protect the domestic economy (Shimp \& Sharma, 1987), or anti-global consumers, who loath product homogenization brought about by global brands (Dimofte et al., 2008; Holt et al., 2004). Recent trends highlight consumers' need for authenticity and product originality (Nijssen \& Douglas, 2011) as well as their desire to "return to the roots" and re-embrace their local communities also represent promising opportunities for local brands' competitive position (Steenkamp \& de Jong, 2010).

Perceived brand localness refers to the extent to which a brand is "being recognized as a local player and a symbol or icon of the local culture" (Swoboda et al., 2012, p.72). Perceived as "local" ascribes brands with perceptions of cultural originality, national identification and local community support (Ger, 1999; Schuiling \& Kapferer, 2004). In many cases, local brands are not perceived merely as brands of restricted regional availability but stand as proud representatives of the local community (Dimofte et al., 2008). Especially, brands perceived as cultural icons of the local country benefit from perceptions of higher prestige and positive affect (Özsomer, 2012;

Steenkamp et al., 2003). Such brands are highly valued because they enable consumers to express their identity and also generate high levels of brand trust (Xie et al., 2015). Another key strength 
of local brands is their ability to adapt to local tastes and satisfy idiosyncratic local preferences that global brands are unable to meet (Dimofte et al., 2008; Schuiling \& Kapferer, 2004). Overall, local brands appear more connected to local consumers, have strong cultural links with the local communities and benefit from the superior knowledge about local preferences through their longlasting presence in the local market. Importantly, the positive effects of brand localness on brand preference appear particularly strong not only in developed countries but also in many emerging markets (e.g. China, India, etc.) (Özsomer, 2012; Swoboda et al., 2012). Thus, we expect that favorable local brand associations will lead to greater purchase intentions through their positive effect on consumer attitudes.

$\mathrm{H}_{1 \mathrm{~b}}$ : Perceived brand localness has a positive effect on purchase intentions by generating more positive brand attitudes.

In line with previous research (Özsomer, 2012; Steenkamp et al., 2003; Swoboda et al., 2012; Xie et al., 2015), we do not view brand globalness and localness as standing on the opposite sides of the same continuum. As Dimofte et al. (2008, p.120) note, "a local brand is not simply the opposite of a global brand". Attesting to this notion, several brands may carry both globalness and localness perceptions either by combining global availability with domestic origin (e.g., Coca-Cola for Americans) or by somehow adapting to the local market despite being global (e.g., McDonald's emphasizes the use of local ingredients in the various country markets it operates). Consequently, we include perceived brand globalness and perceived brand localness as distinct drivers of attitudes and intentions in our model (see also Özsomer, 2012; Swoboda et al., 2012; Xie et al., 2015). 


\subsection{Country-specific factors: Country warmth and country competence}

A large body of research has demonstrated that $\mathrm{COO}$ cues may render symbolic value to the brand, act as a signal of quality, affect perceptions of risk associated with a purchase, and influence consumer preferences (Maheswaran \& Chen, 2009; Wilcox, 2015). The mechanism behind $\mathrm{COO}$ effects is based on the idea that individuals associate different countries and their people with different attributes which intuitively transfer to how they perceive products coming from these countries (Maheswaran, 1994).

Stereotype theory in social psychology offers a promising conceptual domain for studying COO effects (Herz \& Diamantopoulos, 2013; Maheswaran, 1994). A stereotype is an oversimplified set of beliefs about the characteristics of any social category that is largely shared within a given population; the content of the stereotype (i.e., stereotypical characteristics) is generally assumed to apply uniformly to every individual member that belongs to the category (Greenwald \& Banaji, 1995). To illustrate, given the stereotype that Japanese people are hardworking and disciplined, every time we encounter an individual coming from Japan we will tend to assume that (s)he has these qualities. Consistent with the notion of stereotyping, stereotypical associations do not only apply to people but also to every stimulus object that is ascribed to the stereotypical category. Therefore, if we identify a brand's country of origin, stereotypical country beliefs will transfer to our product impressions and lead to inferences about the features and nature of the product (Herz \& Diamantopoulos, 2013; Liu \& Johnson, 2005).

The Stereotype Content Model (SCM; Fiske et al., 2002) is a theoretical framework that describes perception of others along two fundamental stereotypical dimensions which are important predictors of affective and behavioral reactions (Cuddy, Fiske, \& Glick, 2008). According to the SCM, people tend to organize every social group on the basis of warmth and 
competence judgments. The former refers to people's cognitive appraisals about the intention of 'others' to potentially benefit or harm them while the latter reflects the extent to which 'others' are capable to pursue their intentions. The dimension of warmth captures such notions as goodnature, friendliness, and kindness, whereas, the dimension of competence corresponds to the notions of capability, efficiency, and intelligence (Fiske et al., 2007). Overall, the more a social group is perceived as having positive and cooperative intentions, the more it is stereotyped as warm, and the more the group is perceived as having the ability to realize its intention, the more it is stereotyped as competent (Fiske et al., 2002). Stereotype research has suggested that the dimensions of warmth and competence can be applied to different levels of social perception, including impressions of individuals, group-level perceptions, or country-level perceptions (Cuddy et al., 2008).

Although the SCM has been recently employed in marketing research (Aaker, Vohs, \& Mogilner, 2010; Chen, Mathur, \& Maheswaran, 2014), it has found limited application in the area of international marketing (Chattalas et al., 2008). Chattalas and Takada (2013) used the SCM dimensions to predict hedonic and utilitarian product perceptions and demonstrated that warmthrelated country perceptions generate more expectations of hedonic properties, whereas competencerelated country perceptions lead to more utilitarian product expectations. From a different perspective, Chen et al. (2014) found that the impact of country-related affect (CRA) on product evaluations is uniquely determined by whether it is induced by judgments of competence or warmth. Their results demonstrated that competence-based CRA transfers directly to consumer evaluations in a valence-consistent manner, while warmth-based CRA first activates countryproduct associations which, depending on their favorability, then determine product evaluations (Chen et al., 2014). Finally, Maher and Carter (2011) showed that both judgments of a country's 
warmth and competence increase consumers' feeling of admiration toward the COO which is positively linked to willingness to buy products coming from that country.

Overall, COO research is in accordance with the central notion of the SCM suggesting that people tend to positively value social groups characterized by high warmth and high competence (Cuddy et al., 2008). More specifically, the dimension of competence engenders perceptions of a country's ability and efficiency, both of which are typically related to business and manufacturing capabilities (Chen et al., 2014; Wilcox, 2015) and, thus, serve as a diagnostic informational cue of reliable and high quality products. In a similar vein, Heslop and Papadopoulos (1993), and more recently Pappu, Quester, and Cooksey (2007), have argued that macro-level country perceptions consist of beliefs about the indusrtiouness of the country's people, the status of the country's economy, and its technological advancement. These beliefs positively influence key dimensions of brand equity such as perceptions of quality and favorability of brand associations (Maher \& Carter, 2011). Along these lines, we propose that judgments of competence about a brand's COO generate inferences of superior product performance that lead to more favorable attitudes toward the brand. Consistent with Chaudhuri and Holbrook (2001), such favorable brand attitudes will subsequently positively impact consumers' behavioral intentions.

$H_{2 a}$ : Judgments of competence have a positive effect on purchase intentions by generating more positive brand attitudes.

The warmth dimension of the SCM reflects whether a group has a positive or a negative intent (Fiske et al., 2007). Thus, judgments of a country's warmth incorporate how friendly, good-natured, and well-intentioned the country is perceived to be. As also observed by Maher 
and Carter (2011), previous marketing studies have misidentified warmth as an affective dimension of country stereotypes. For instance, building on Heslop and Papadopoulos’ (1993) work, Chattalas et al. (2008) conceptualized country affect to be "analogous to the perceived warmth dimension" (p. 59). Nevertheless, despite the seeming similarity between these constructs, judgments of warmth represent a cognitive assessment of the favorability of another group's intentions toward one's own group; these judgments act as antecedents of subsequent affective reactions (Chen et al., 2014; Cuddy et al., 2008).

From an international marketing perspective, unlike competence, the dimension of warmth is perceived to be nondiagnostic to a country's product quality and performance (Chen et al., 2014). However, we anticipate that perceptions of high COO warmth produce a general liking for the country that could also potentially transfer to attitudes toward its products. More specifically, judgments of warmth signal a benign country which is seen as friendly and goodnatured (Cuddy et al., 2008) and such cognitive appraisals contribute to the overall favorability toward that country (Chen et al., 2014). Through a 'halo effect' (Nisbett \& Wilson, 1977), the favorable country predisposition should positively influence consumer attitudes for products coming from that country (Maher \& Carter, 2011), which are then expected to positively impact brand purchase intentions.

$H_{2 b}$ : Judgments of warmth have a positive effect on purchase intentions by generating more positive brand attitudes. 


\title{
3. Empirical study
}

\author{
3.1 Methodology
}

Two hundred fifty-three consumers in Austria (148 female, $M_{\text {age }}=30.78, S D=11.75$ ) were recruited in a between-subjects study. Respondents were randomly assigned to one out of six different product categories (soft drinks, laptops, shampoos, clothing, chocolate bars, cars) and completed a self-administered questionnaire that assessed their perceptions about a real brand and its corresponding country of origin (Fanta/USA, Samsung/South Korea, Schwarzkopf/Germany, Zara/Spain, Snickers/USA, Toyota/Japan). The product categories were chosen in order to be comparable with those used in previous relevant literature (e.g., Alden et al., 1999; Herz \& Diamantopoulos, 2013; Pappu et al., 2007; Özsomer, 2012) and covered a wide range of consumer goods so as to avoid category specificity and, thus, enhance the generalizability of findings.

The selected stimulus brands had to satisfy a number of criteria. First, to account for diverse brand origins, we took into consideration brands from countries across different continents, namely America, Europe, and Asia. Second, to ensure variability in brand globalness/localness as well as presence of distinct country stereotypes, we focused on brands coming from countries with which respondents were sufficiently familiar. Unstructured pilot interviews with a small group of consumers conducted prior to the main study, indicated that the target brands (and corresponding COOs) were suitable, while main study results showed that respondents were adequately familiar both with the stimulus brands and the associated countries $\left(M_{\text {brands }}=4.93, S D=1.73\right.$ and $M_{\text {countries }}=4.15, S D=1.77 ; 1=$ not at all familiar $/ 7=$ highly familiar). 
Questionnaire completion was undertaken in two stages. First, respondents were asked to rate each target brand in terms of perceived brand globalness, perceived brand localness, attitude toward the brand, and brand purchase intention. In addition, given that the study employed real brands, for which respondents might have prior experience, the level of brand familiarity was also measured to control for any confounding effects of prior brand knowledge (Steenkamp et al. 2003). Table 1 provides details for the measurement scales used in the study.

\section{TABLE 1 ABOUT HERE}

The second stage involved the stereotype identification process for the brands' COO based on the dimensions of the SCM, namely warmth and competence. Although these two dimensions are usually conceptualized as orthogonal, research on group- or cultural-level judgments points toward a mixed stereotype content (Aaker et al., 2010; Fiske et al., 2002): a social group is usually perceived either as predominantly warm or predominantly competent but not both (Judd, James-Hawkings, Yzerbyt, \& Kashima, 2005). To facilitate the generation of mixed stereotypes, each target country was presented along with another reference country with a supposedly different stereotypical profile (e.g., Spain/Sweden and Japan/France). Respondents were given a list of attributes that are used to describe people's perception of other social groups and engaged in a mutually exclusive allocation task. More specifically, respondents were asked to assign each attribute to either the target or the reference country based on how most people in their society see these countries (Fiske et al., 2002). In line with similar COO studies using the SCM (Chattalas \& Takada, 2013; Maher \& Carter, 2011), four attributes captured perceptions of competence (capable, efficient, intelligent, competent) and four attributes (friendly, good-

natured, kind, warm) captured perceptions of warmth. Attribute allocations for each dimension 
were aggregated to form an overall index for warmth and competence for each respondent. Overall, scores ranged between 0 (no attribute allocated) and 4 (all four attributes allocated), with higher (lower) scores indicating more (less) of the SCM dimension being measured. The order of appearance between the target and the reference country as well as the order of attribute presentation was counterbalanced to avoid carry-over effects.

\subsection{Results}

Consistent with prior research in the field (Steenkamp et al., 2003) and relevant methodological literature (Anderson \& Gerbing, 1988), we operationalized our constructs with single composite indicators derived through parceling (averaging) the individual scale items. To account for error variance, we set the composite indicator error variances at levels determined by the composite's variance $\left(\sigma^{2}\right)$ and alpha reliability $(\alpha)$ coefficient (error variance $=(1-\alpha) \times \sigma^{2}$; Anderson \& Gerbing, 1988) as this approach provides accurate structural parameter estimates (Bandalos, 2002). Cronbach's alphas indicated high reliabilities for all model constructs $\left(\alpha_{P B G}=\right.$ $\left.0.79, \alpha_{P B L}=0.66, \alpha_{B A T T}=0.92, \alpha_{P I}=0.87\right)$. Descriptive statistics and inter-construct correlations are presented in Table 2 .

\section{TABLE 2 ABOUT HERE}

We estimated the model of Figure 1 using LISREL 8.80 and obtained very good model fit $\left(\chi^{2}=9.892, d f=4, p=0.042, R M S E A=0.076, G F I=0.989, C F I=.984, S R M R=0.023\right)$.

Regarding the individual hypotheses, we find that both perceived brand globalness and perceived brand localness have a positive effect on brand attitude $\left(\beta_{P B G \rightarrow B A T T}=.16, p<.01 ; \beta_{P B L \rightarrow B A T T}=.29\right.$, $p<.001)$. In turn, brand attitude has a strong positive effect on purchase intentions $\left(\beta_{B A T T \rightarrow P I}=\right.$ 
$.75, p<.001)$, leading to significant indirect effects of perceived brand globalness $\left(\beta_{P B G \rightarrow B A T T \rightarrow P I}\right.$ $=.12, p<.01)$ and perceived brand localness $\left(\beta_{P B L \rightarrow B A T T \rightarrow P I}=.22, p<.001\right)$ on PI. Thus, $\mathrm{H}_{1 \mathrm{a}}$ and $\mathrm{H}_{1 \mathrm{~b}}$ are both supported.

Competence exerts a positive influence on brand attitude $\left(\beta_{\text {COMP } \rightarrow B A T T}=.09, p<.05\right)$ and through brand attitude, it has an indirect effect on purchase intentions $\left(\beta_{C O M P \rightarrow B A T T \rightarrow P I}=.07, p<\right.$ .05). However, warmth has no effect on brand attitude $\left(\beta_{C O M P \rightarrow B A T T}=.04\right.$, ns $)$ and, thus, does not impact purchase intentions. Consequently, we find support for $\mathrm{H}_{2 \mathrm{a}}$ but not for $\mathrm{H}_{2 \mathrm{~b}}$. These effects are obtained after controlling for brand familiarity (BFAM) which is a significant determinant of both brand attitude $\left(\beta_{B F A M \rightarrow B A T T}=.50, p<.001\right)$ and purchase intentions $\left(\beta_{B F A M \rightarrow P I}=.12, p<.05\right)$. Overall, our model accounts for $44.7 \%$ of variability in brand attitude and $67.9 \%$ of variability in purchase intentions. Table 3 summarizes the estimation results.

\section{TABLE 3 ABOUT HERE}

We formally compared the magnitudes of the effects of perceived brand globalness, brand localness and country competence on brand attitude by comparing the fit of the base model in Figure 1 with models incorporating pairs of equality constraints between two predictors at a time and noting the respective change in model $\chi^{2}$. Perceived brand globalness and competence appear to have similar effects on brand attitude (PBG vs. COMP: $\Delta \chi^{2}=1.28, d f=1, p=.26$ ). In contrast, brand localness appears to have a significantly stronger effect on brand attitude than both brand globalness and competence (PBL vs. PBG: $\Delta \chi^{2}=5.85, d f=1, p=.02$; PBL vs.

COMP: $\left.\Delta \chi^{2}=9.30, d f=1, p<.001\right)$. We also compared the base model with another model where all the paths from the three significant predictors on brand attitude were set equal. The 
change in model fit is significant $\left(\Delta \chi^{2}=9.35, d f=2, p=.01\right)$, further confirming that the effects of the included predictors on brand attitude are not equally strong.

Finally, to explore potential interactions between brand- and country-related factors, we estimated the effects of all relevant interactions terms (PBG $\times$ COMP, $\mathrm{PBG} \times \mathrm{WARM}$, PBL $\times$ COMP, PBL $\times W A R M)$ on brand attitude. With regard to brand localness, we find no significant interactions $\left(\beta_{P B L \times C O M P}=.01, p=.859 ; \beta_{P B L \times W A R M}=-.03, p=.448\right)$. Apparently, the positive influence of brand localness on brand attitude is constant, irrespective of the levels of competence and warmth. However, a different picture emerges with regard to brand globalness. The interaction of perceived brand globalness with competence is not significant $\left(\beta_{P B G \times C O M P}=-\right.$ $.04, p=.170)$ while its interaction with warmth is $\left(\beta_{P B G \times W A R M}=.08, p=.009\right)$. Probing this interaction at the discrete values of the WARM index (Spiller, Fitzsimons, Lynch, \& McClelland, 2013 ) indicates that for low and moderate levels of country warmth (i.e., for WARM index values between 0 and 2) the effect of perceived brand globalness on brand attitude is not significant. For higher levels of country warmth (i.e., for WARM index values of 3 and 4), however, perceived brand globalness has a significant positive effect on brand attitude. The interaction effects are graphically displayed in Figure 2.

FIGURE 2 ABOUT HERE

\section{Discussion and conclusions}

\subsection{Theoretical implications}

Bringing together research on global branding and COO, our study contributes to international marketing literature in several ways. First, in response to the recent debate regarding 
the relevance of COO in an era of global brands (Samiee, 2011; Usunier \& Cestre, 2008; Wilcox, 2015), we empirically show that country perceptions do play a significant role in the formation of brand attitude, even after the influence of brand globalness/localness is explicitly accounted for. This finding has two important implications. On the one hand, it shows that both research domains are relevant in shaping our understanding of how consumers make decisions in an international marketplace and, therefore, bringing these fields together in future studies should be beneficial. On the other hand, it indicates that $\mathrm{COO}$ and perceived brand globalness/localness have complementary and mutually reinforcing effects on consumer responses. This suggests that rather than debating about whether the globalness of a brand is a more important than its origin (or vice versa), the focus should be on determining their relative strength as well as the specific conditions under which one is more likely to dominate over the other.

Second, extending previous applications of the SCM in the international marketing field (Chattalas \& Takada, 2013; Chen et al., 2014; Maher \& Carter, 2011), we empirically demonstrate that the SCM is a valid theoretical framework that can be used across consumer contexts to systematically study COO effects. Specifically, consistent with previous relevant studies, we find that judgments of competence, but not warmth, have a significant positive influence on brand attitudes (Maher \& Carter, 2011). This further corroborates the notion that warmth-related country judgments are more difficult to directly link to the assessment of products, whereas competence-related judgments can be readily associated with a country's ability to deliver high quality products and, thus, exert a strong influence on brand attitudes (Chen et al., 2014). Consistent with previous research on COO (e.g., Maher \& Carter, 2011) and global branding (e.g., Steenkamp et al., 2003), brand origin perceptions and perceived brand globalness/localness represent extrinsic attributes that essentially contribute to the general impression of the brand. Chaudhuri and Holbrook (2001) suggest that such positive (negative) overall evaluations should 
then encourage (discourage) behavioral intentions. In line with this notion, our findings show that positively valenced country stereotypes and globalness/localness perceptions generate more positive responses toward the brand, as captured by consumers' overall brand attitude, which subsequently translate into higher purchase intention.

Third, addressing research calls to investigate not only the relative strength but also the interaction between COO and other extrinsic brand cues (Wilcox, 2015), our research provides exploratory evidence indicating that country stereotypes interact with perceptions of globalness in determining overall brand attitude. More specifically, our findings suggest that for brands whose origin country is perceived as warm, brand globalness affects brand attitudes more strongly than for brands originating from countries stereotypically perceived as not warm. This interaction implies that country stereotypes and brand globalness might be operating in a compensatory manner. That is, given the less diagnostic nature of warmth judgments with regard to product decisions, brand globalness appears to function as a surrogate factor that offers consumers easily accessible and diagnostic information for brand attitude formation (Swoboda et al., 2012). The importance of this information appears to increase the more dominant the warmth dimension is in the content of the country stereotype. These findings suggest that it may be premature to discount the relevance of the warmth dimension in the consumer behavior context, as recent studies seem to imply (Chen et al., 2014).

Finally, in line with previous studies (Özsomer, 2012; Steenkamp et al., 2003; Swoboda et al., 2012; Xie et al., 2015), we identify a strong influence of perceived brand localness on brand preference. However, unlike research treating localness merely as a counter-strategy to global brands, we find that brand localness is a strong attitudinal driver not just for locally available brands but also for international brands, such as those used in our study. In fact, our findings show that perceived brand localness has a stronger influence on brand attitudes than globalness 
and, thus, a stronger total effect on purchase intentions. Moreover, unlike brand globalness, whose influence is conditioned by stereotypical judgments of warmth, the impact of brand localness is unaffected by country stereotypes. This seems to suggest that global brands can benefit from localness associations regardless of the stereotype content consumers hold about the brand's origin.

\subsection{Managerial implications}

From a managerial perspective, our findings indicate that positioning the brand on the basis of globalness/localness or by associating the brand with a competent $\mathrm{COO}$ are both effective strategies to create brand value. Prior research has identified ways through which brands can be associated with global symbols to represent icons of the global consumer culture or cultivate links with the local community to emerge as representatives of the local culture (Alden, Steenkamp, \& Batra, 1999). Similarly, cues linking the brand to a particular country can help transfer any favorable association from the country to the brand (Herz \& Diamantopoulos, 2013; Liu \& Johnson, 2005). Our findings show that both positioning strategies are relevant to consumers and should, therefore, be equally considered as positioning alternatives.

Adopting either a global or a local consumer culture positioning strategy is likely to be beneficial through the generation of high globalness or high localness brand associations, both of which positively impact brand attitudes and behavioral intentions. However, given the significantly stronger effect of localness observed in our study, managers should consider investing more heavily on developing links with the local communities and should show an honest effort to adjust to the local consumer base (Ger, 1999). Such investments can pay off not only for traditional local/domestic brands but also for international brands which can find creative ways to relate to the local market. Interesting such examples include Danone which adopts local 
production methods in its operations and incorporates local ingredients in its products across local markets, or Honda which promotes itself as a growth engine for the American economy because of its long-lasting investments in US-based sourcing, R\&D and manufacturing.

Regarding positioning with reference to a particular COO, brands can take advantage of product ethnicity effects (Usunier \& Cestre, 2007) or build on favorable country images (Han, 1989). In this context, the SCM offers a promising analytical tool for assessing how brands can capitalize on stereotypical country beliefs (Chattalas et al., 2008; Maher \& Carter, 2011). Specifically, using the dimensions of the SCM, marketing managers can systematically analyze the content of consumers' country stereotypes and couple them with other brand-related characteristics to make optimal decisions in terms of which dimension of the brand's origin should be highlighted or downplayed in the positioning and communication strategies developed.

Finally, a finding with particular managerial relevance is that locally connected brands are favorably perceived regardless of consumer stereotype about the brands' origin. Thus, building on brand localness might be particularly beneficial for products originating from countries with weak or unfavorable stereotypes. In contrast, perceived brand globalness interacts with country stereotypes, such that a global positioning strategy appears to be more effective when warmth judgments dominate the content of the COO stereotype. In other words, global brand positioning for brands coming from typically "warm" countries (e.g., Spain or Italy) seems more beneficial than for those coming from stereotypically "competent" countries (e.g., Germany or Japan).

\subsection{Limitations and future research}

The present study is the first to simultaneously consider perceptions of brand globalness/localness and stereotypes of the brand's origin. As such, the findings presented herein 
are by no means conclusive and are subject to a number of limitations that indicate directions for future research. First, although we used multiple brands from different countries and across various product categories, our results are based on a sample from a single economicallydeveloped, west-European country. Replication of the study in different country contexts, such as in an emergent market, is necessary to establish the generalizability of findings. Such replications are important since there is evidence to suggest that brand globalness and/or localness perceptions may operate differently in mature and emergent markets (Özsomer, 2012) and, therefore, the magnitude of their effects may differ across contexts.

Second, our study highlights the need for further research with regard to the notion of brand localness as well as its operationalization. The amount of attention given to brand localness (Özsomer, 2012; Steenkamp et al., 2003; Swoboda et al., 2012; Xie et al., 2015) seems to be disproportionately low to the strength of its effects, at least as documented in the present paper. Researchers are encouraged to further explore $(a)$ the conceptual nature of the "localness" construct and the identification of its key components or dimensions (e.g., regional availability, local iconness, domestic origin, local adaptation), (b) the mechanism through which each component impacts perceived brand value, and $(c)$ the conditions under which perceptions of brand localness can be more or less effective than brand globalness in building brand equity.

Third, consistent with previous research (Chen et al., 2014; Maher \& Carter, 2011) our study did not reveal any direct significant influence of country warmth on brand evaluations. Maher and Carter (2011) suggest that the impact of warmth is more likely to be manifested in emotional responses (e.g., feelings of admiration or envy) toward the brand's origin which, however, were not accounted for in the present study. That said, how the dimension of warmth works in a marketing context, both in terms of its effects and with regard to the processes underlying tis effects, remains an important question for future research. It should also be noted 
here that even though the procedure followed to capture warmth and competence facilitated the elicitation and identification of distinct country stereotypes, it did not allow for the assessment of the psychometric properties of the these dimensions. Future studies should employ alternative operationalizations and provide insights on how to best capture stereotypical country perceptions.

Fourth, given that brand globalness, localness and country stereotypes are all relevant predictors of consumer preference, researchers should further focus on the conditions under which each of these predictors is stronger than the others. That is, future investigations should identify the role of potential moderating variables, such as consumer ethnocentrism (Shimp \& Sharma, 1987), consumer dispositions toward globality (Bartsch, Riefler, \& Diamantopoulos, 2016) or product nature (e.g., experiential vs. conventional products; Holbrook \& Hirschman, 1982, and search vs. experience goods; Franke, Huhmann \& Mothersbaugh, 2004), that might increase the salience of either the brand- or the country-related factors and shift the relative strength of predictors within each set of factors.

Finally, the interaction between country- and brand-related variables represents a promising avenue for further research. Our research provided some initial empirical evidence of their interplay but further investigation regarding the theoretical basis of this interplay is needed. Is perceived brand globalness able to counterbalance the effects of an unfavorable country image or a negative stereotype? Do consumers view brand globalness and country stereotypes as "substitute" qualities, such that when one is absent consumers can turn to the other to fill the void? Answers to such questions will contribute to our understanding of how consumers make decisions in an international marketplace and, consequently, how companies should develop effective brand positioning and communication strategies. 


\section{References}

Aaker, J., Vohs, K. D., \& Mogilner, C. (2010). Nonprofits are seen as warm and for-profits as competent: Firm stereotypes matter. Journal of Consumer Research, 37(2), 224-237.

Alden, D. L., Steenkamp, J. B. E., \& Batra, R. (1999). Brand positioning through advertising in Asia, North America, and Europe: The role of global consumer culture. Journal of Marketing, 63(1), 75-87.

Alden, D. L., Steenkamp, J. B. E. M., \& Batra, R. (2006). Consumer attitudes toward marketplace globalization: Structure, antecedents and consequences. International Journal of Research in Marketing, 23(3), 227-39.

Anderson, J. C., \& Gerbing, D. W. (1988). Structural equation modeling in practice: A review and recommended two-step approach. Psychological Bulletin, 103(3), 75-87.

Bandalos, D. L. (2002). The effects of item parceling on goodness-of-fit and parameter estimate bias in structural equation modeling. Structural Equation Modeling, 9(1), 78-102.

Bartsch, F., Riefler, P., \& Diamantopoulos, A. (2016). A taxonomy and review of positive consumer dispositions toward foreign countries and globalization. Journal of International Marketing, (forthcoming), doi: http://dx.doi.org/10.1509/jim.15.0021

Chattalas, M., Kramer, T., \& Takada, H. (2008). The impact of national stereotypes on the country of origin effect: A conceptual framework. International Marketing Review, 25(1), 54-74.

Chattalas, M., \& Takada, H. (2013). Warm versus competent countries: National stereotyping effects on expectations of hedonic versus utilitarian product properties. Place Branding and Public Diplomacy, 9(2), 88-97.

Chaudhuri, A., \& Holbrook, M. B. (2001). The chain of effects from brand trust and brand affect to brand performance: the role of brand loyalty. Journal of Marketing, 65(2), 81-93. 
Chen, C. Y., Mathur, P., \& Maheswaran, D. (2014). The effects of country-related affect on product evaluations. Journal of Consumer Research, 41(4), 1033-1046.

Cuddy, A. J. C., Fiske, S. T., \& Glick, P. (2008). Warmth and competence as universal dimensions of social perception: The stereotype content model and the BIAS map. Advances in Experimental Social Psychology, 40, 61-149.

Davvetas, V., Sichtmann, C., \& Diamantopoulos, A. (2015). The impact of perceived brand globalness on consumers' willingness to pay. International Journal of Research in Marketing, 32(4), 431-434.

Dimofte, C. V., Johansson, J. K., \& Ronkainen, I. A. (2008). Cognitive and affective reactions of U.S. consumers to global brands. Journal of International Marketing, 16(4), 113-35.

Fiske, S. T., Cuddy, A. J., \& Glick, P. (2007). Universal dimensions of social cognition: Warmth and competence. Trends in cognitive sciences, 11(2), 77-83.

Fiske, S. T., Cuddy, A. J. C., Glick, P., \& Xu, J. (2002). A model of (often mixed) stereotype content: competence and warmth respectively follow from perceived status and competition. Journal of Personality and Social Psychology, 82(6), 878-902.

Franke, G. R., Huhmann, B. A., \& Mothersbaugh, D. L. (2004). Information content and consumer readership of print ads: a comparison of search and experience products. Journal of the Academy of Marketing Science, 32(1), 20-31.

Fuchs, C., \& Diamantopoulos, A. (2010). Evaluating the Effectiveness of Brand Positioning Strategies from a Consumer Perspective. European Journal of Marketing, 44(11/12), 17631786.

Ger, G. (1999). Localizing in the global village: Local firms competing in global markets. California Management Review, 41(4), 64-83. 
Greenwald, A. G., \& Banaji, M. R. (1995). Implicit social cognition: attitudes, self-esteem, and stereotypes. Psychological Review, 102(1), 4-27.

Han, C. M. (1989). Country image: Halo or summury construct? Journal of Marketing Research, 26(2), 222-229.

Herz, M. F., \& Diamantopoulos, A. (2013). Activation of country stereotypes: automaticity, consonance, and impact. Journal of the Academy of Marketing Science, 41(4), 400-417.

Heslop, L. A., \& Papadopoulos, N. (1993). But who knows where or when? Reflections on the images of countries and their products. In N. Papadopoulos \& L. A. Heslop (Eds.), Productcountry images: Impact and role in international marketing (pp. 39-75). New York: Routledge.

Holt, D. B., Quelch, J. A., \& Taylor, E. L. (2004). How global brands compete. Harvard Business Review, 82(September), 68-75.

Holbrook, M. B., \& Hirschman, E. C. (1982). The experiential aspects of consumption: Consumer fantasies, feelings, and fun. Journal of Consumer Research, (9)2, 132-140.

Jaffe, E. D., \& Nebenzahl, I. D. (2006). National image and competitive advantage: the theory and practice of place branding ( $2^{\text {nd }}$ ed.). Copenhagen: Copenhagen Business School Press.

Judd, C. M., James-Hawkins, L., Yzerbyt, V., \& Kashima, Y. (2005). Fundamental dimensions of social judgment: understanding the relations between judgments of competence and warmth. Journal of Personality and Social Psychology, 89(6), 899-913.

Leclerc, F., Schmitt, B. H., \& Dubé, L. (1994). Foreign branding and its effects on product perceptions and attitudes. Journal of Marketing Research, 31(2), 263-270.

Liu, S. S., \& Johnson, K. F. (2005). The automatic country-of-origin effects on brand evaluations. Journal of Advertising, 34(1), 87-97.

Maher, A. A., \& Carter, L. L. (2011). The affective and cognitive components of country image: Perceptions of American products in Kuwait. International Marketing Review, 28(6), 559-580. 
Maheswaran, D. (1994). Country of origin as a stereotype: effects of consumer expertise and attribute strength on product evaluations. Journal of Consumer Research, 21(2), 354-365.

Maheswaran, D., \& Chen, C. Y. (2009). Nation equity: Country-of-origin effects and globalization. In M. Kotabe \& K. Kelsen (Eds.), Handbook of international marketing (pp. 91-113). Thousand Oaks, CA: Sage.

Nijssen, E.J., \& Douglas, S.P. (2011). Consumer world-mindedness and attitudes toward product positioning in advertising: An examination of global versus foreign versus local positioning. Journal of International Marketing, 19(3), 113-133.

Nisbett, R. E., \& Wilson, T. D. (1977). The halo effect: Evidence for unconscious alteration of judgments. Journal of personality and social psychology, 35(4), 250-256.

Özsomer, A. (2012). The interplay between global and local brands: A closer look at perceived brand globalness and local iconness. Journal of International Marketing, 20(2), 72-95.

Özsomer, A., \& Altaras, S. (2008). Global brand purchase likelihood: A critical synthesis and an integrated conceptual framework. Journal of International Marketing, 16(4), 1-28.

Pappu, R., Quester, P. G., \& Cooksey, R. W. (2007). Country image and consumer-based brand equity: relationships and implications for international marketing. Journal of International Business Studies, 38(5), 726-745.

Petrevu, S., \& Lord, K. R. (1994). Comparative and non-comparative advertising: Attitudinal effects under cognitive and affective involvement conditions. Journal of Advertising, 23(2), 77-90.

Riefler, P. (2012). Why consumers do (not) like global brands: The role of globalization attitude, GCO and Brand Origin. International Journal of Research in Marketing, 29(1), 25-34.

Samiee, S. (2011). Resolving the impasse regarding research on the origins of products and brands. International Marketing Review, 28(5), 473-485. 
Schuiling, I., \& Kapferer, J. N. (2004). Executive Insights: Real Differences Between Local and International Brands: Strategic Implications for International Marketers. Journal of International Marketing, 12(4), 97-112.

Shimp, T. A., \& Sharma, S. (1987). Consumer ethnocentrism: Construction and validation of the CETSCALE. Journal of Marketing Research, 24(3), 280-89.

Sichtmann, C., \& Diamantopoulos, A. (2013). The impact of perceived brand globalness, brand origin image, and brand origin-extension fit on brand extension success. Journal of the Academy of Marketing Science, 41(5), 567-585.

Spiller, S. A., Fitzsimons, G. J., Lynch J. G. Jr., \& McClelland, G. H. (2013). Spotlights, floodlights, and the magic number zero: Simple effects in moderated regression. Journal of Marketing Research, 50, 277-288.

Steenkamp, J. E. B., \& de Jong, M. G. (2010). A global investigation into the constellation of consumer attitudes toward global and local product. Journal of Marketing, 74, 18-40.

Steenkamp, J. E. B., Batra, R. \& Alden, D.L. (2003). How perceived brand globalness creates brand value. Journal of International Business Studies, 34, 53-65.

Strizhakova, Y., \& Coulter, R. A. (2014). Drivers of local relative to global brand purchases: A contingency approach. Journal of International Marketing, 23(1), 1-22.

Swoboda, B., Pennemann, K., \& Taube, M. (2012). The effects of perceived brand globalness and perceived brand localness in china: Empirical evidence on Western, Asian, and Domestic retailers. Journal of International Marketing, 20(4), 72-95.

Usunier, J.-C. (2006). Relevance in business research: the case of country-of-origin research in marketing, European Management Review, 3(1), 60-73.

Usunier, J.-C. \& Cestre, G. (2007). Product ethncity: Revisiting the match between products and countries. Journal of International Marketing, 15(3), 32-72. 
Usunier, J.-C. \& Cestre, G. (2008), Further considerations on the relevance of country-of-origin research, European Management Review, 5 (4), 271-4.

Van Ittersum, K., \& Wong, N. (2010). The Lexus or the olive tree? Trading off between global convergence and local divergence. International Journal of Research in Marketing, 27(2), 107-118.

Wilcox, D. (2015). Country-Of-Origin Bias: A Literature Review and Prescription for the Global World. In H. E. Spotts (Ed.), Marketing, Technology and Customer Commitment in the New Economy (pp. 86-96): Springer International Publishing.

Xie, Y., Batra, R., \& Peng, S. (2015). An extended model of preference-formation between global and local brands: The roles of identity expressiveness, trust and affect. Journal of International Marketing, 23(1), 50-71. 
Figure 1: Conceptual model

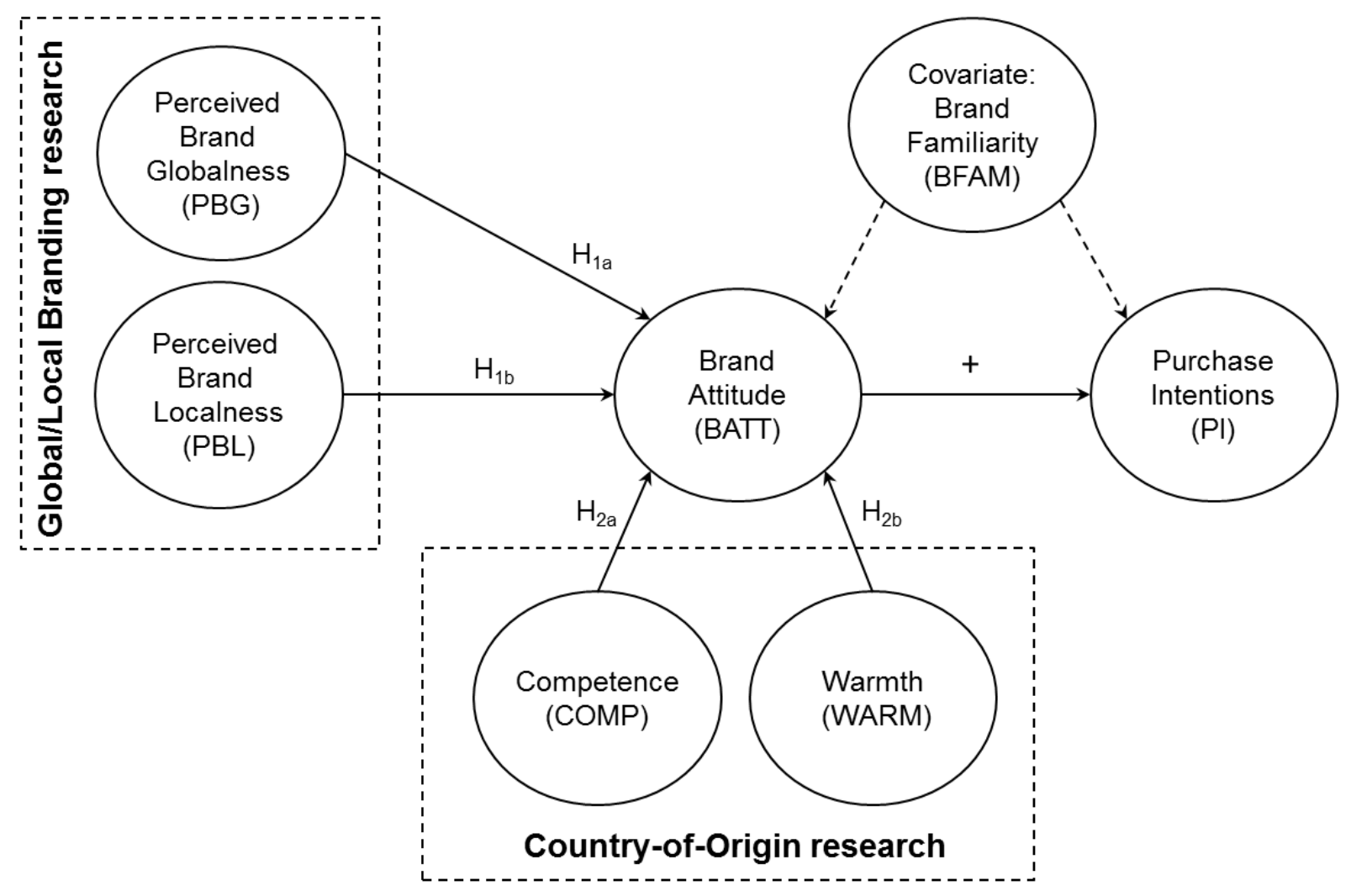


Figure 2: The interaction between perceived brand globalness and competence/warmth judgments

PANEL A: Interaction between PBG and COMP

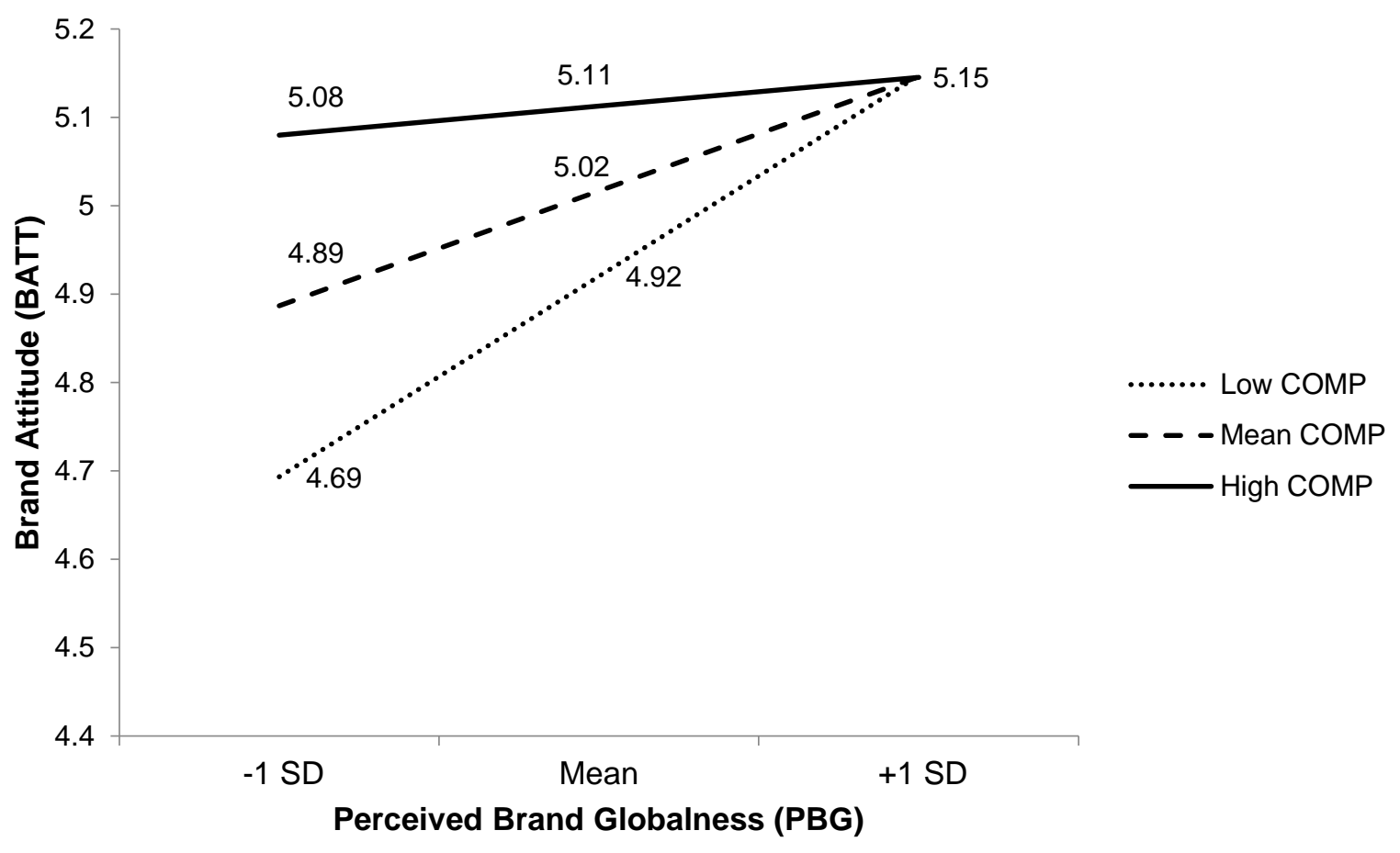

PANEL B: Interaction between PBG and WARM

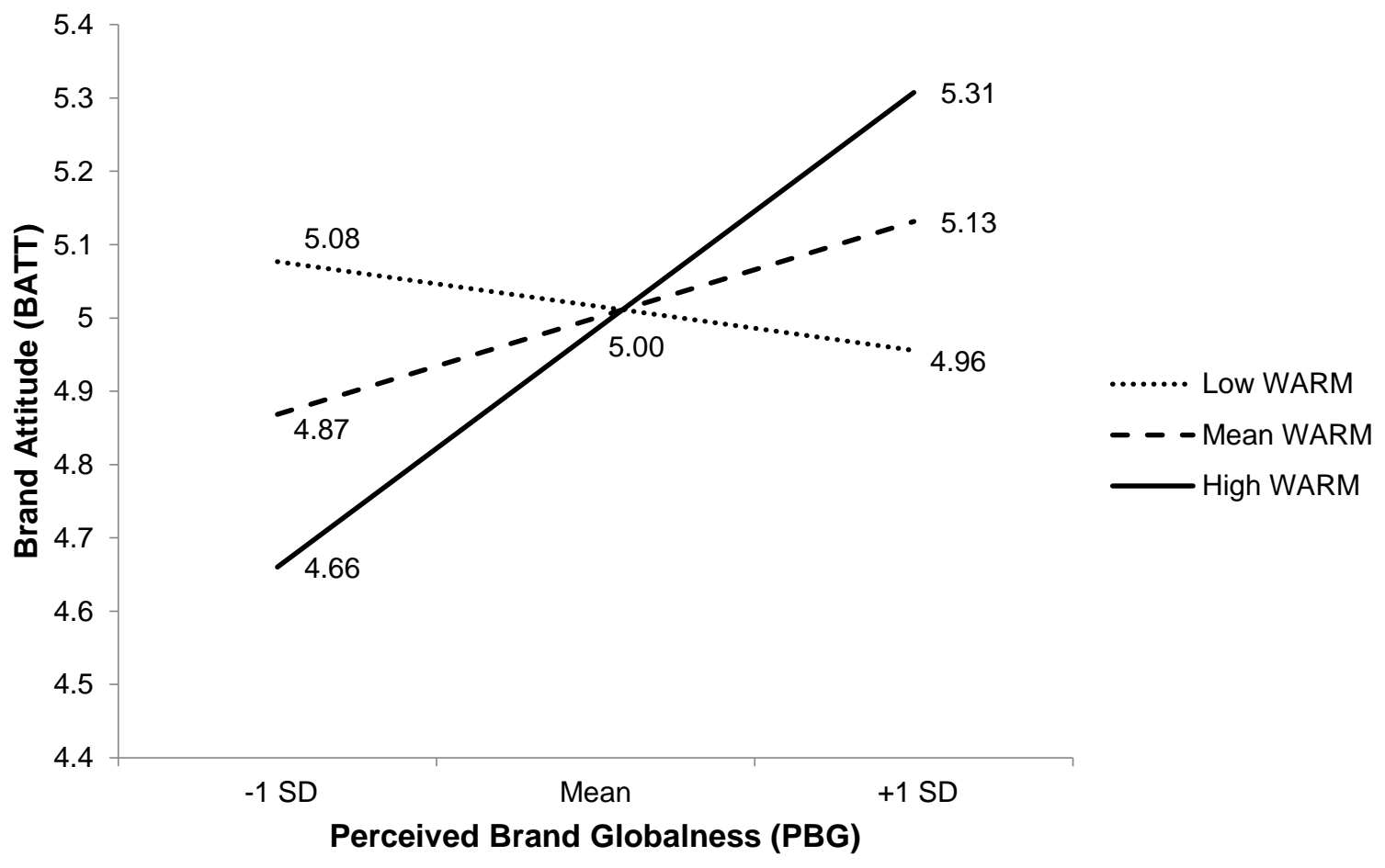


Table 1: Construct measurement

Perceived Brand Globalness (PBG), adapted from Steenkamp et al. (2003), $\alpha=.79$

To me, this brand is local/global.

I don't/do think consumers around the world buy this brand.

This brand is sold only in [country]/all over the world.

Perceived Brand Localness (PBL), adapted from Swoboda et al. (2012), $\alpha=.66$

I associate this brand with Austria.

This brand is part of the Austrian culture.

Brand Attitude (BATT), adapted from Fuchs \& Diamantopoulos (2010), $\alpha=.92$

My opinion about this brand is negative / positive.

This is a bad/good brand.

I don't/do like this brand.

Purchase Intentions (PI), adapted from Petrevu \& Lord (1994), $\alpha=.87$

It is very likely I will buy this brand in the future.

I will buy this brand the next time I need a product from this category.

I will definitely try this brand.

\section{Brand Familiarity (BFAM)}

How familiar do you feel with this brand? (Not familiar at all/Highly familiar)

Note: All items were measured on 7-point scales 
Table 2: Descriptive statistics and correlation matrix

\begin{tabular}{l|c|c|ccccccc}
\hline & M & SD & PBG & PBL & COMP & WARM & BATT & PI & BFAM \\
\hline PBG & 5.77 & 1.49 & 1 & & & & & & \\
PBL & 2.78 & 1.16 & $-.149^{*}$ & 1 & & & & & \\
COMP & 1.91 & 1.62 & $-.127^{*}$ & -.008 & 1 & & & & \\
WARM & 2.06 & 1.56 & $.147^{*}$ & $-.111^{\dagger}$ & $-.300^{* * *}$ & 1 & & & \\
BATT & 5.03 & 1.38 & $.164^{*}$ & $.288^{* * *}$ & .073 & -.023 & 1 & 1 & 1 \\
PI & 3.65 & 1.70 & $.081^{*}$ & $.308^{* * *}$ & -.037 & .015 & $.729^{* * *}$ & 1 \\
BFAM & 4.93 & 1.73 & $.162^{*}$ & $.220^{* * *}$ & .018 & -.034 & $.582^{* * *}$ & $.534^{* * *}$ & 1 \\
\hline
\end{tabular}

${ }^{* * *} p<.001,{ }^{* *} p<.01,{ }^{*} p<.05,{ }^{\dagger} p<.10$. 
Table 3: Estimation results

\begin{tabular}{|c|c|}
\hline \multicolumn{2}{|c|}{ Structural path estimates } \\
\hline \multirow{3}{*}{$\mathrm{PBG} \rightarrow \mathrm{BATT}$} & $\beta=.159$ \\
\hline & $t=2.437$ \\
\hline & $p<.01$ \\
\hline \multirow{3}{*}{$\mathrm{PBL} \rightarrow \mathrm{BATT}$} & $\beta=.287$ \\
\hline & $t=3.911$ \\
\hline & $p<.001$ \\
\hline \multirow{3}{*}{$\mathrm{COMP} \rightarrow \mathrm{BATT}$} & $\beta=.091$ \\
\hline & $t=1.649$ \\
\hline & $p<.05$ \\
\hline \multirow{3}{*}{$\mathrm{WARM} \rightarrow \mathrm{BATT}$} & $\beta=.038$ \\
\hline & $t=.684$ \\
\hline & $p>.10$ \\
\hline \multirow{3}{*}{$\mathrm{BATT} \rightarrow \mathrm{PI}$} & $\beta=.747$ \\
\hline & $t=12.196$ \\
\hline & $p<.001$ \\
\hline \multirow{3}{*}{$\mathrm{BFAM} \rightarrow \mathrm{BATT}$} & $\beta=.499$ \\
\hline & $t=8.484$ \\
\hline & $p<.001$ \\
\hline \multirow{3}{*}{$\mathrm{BFAM} \rightarrow \mathrm{PI}$} & $\beta=.119$ \\
\hline & $t=2.028$ \\
\hline & $p<.05$ \\
\hline
\end{tabular}

Note: $\beta$ s are standardized parameter estimates; $p$-values refer to one-tail tests. 